\title{
P1198: Software for tracing decision behavior in lending to small businesses
}

\author{
PATRIC ANDERSSON \\ Stockholm School of Economics, Stockholm, Sweden
}

\begin{abstract}
This paper describes a process-tracing software program specially designed to capture decision behavior in lending to small businesses. The source code was written in Lotus Notes. The software runs in a Web browser and consists of two interacting systems: a database and a user interface. The database includes three realistic loan applications. The user interface consists of different but interacting screens that enable the participant to operate the software. Log files register the decision behavior of the participant. An empirical example is presented in order to show the software's potential in providing insights into judgment and decision making. The implications of the software are discussed.
\end{abstract}

Researchers in judgment and decision making (JDM) are increasingly using process-tracing software to capture how people make judgments and decisions (Svenson, 1996). Computerized process tracing is basically an advanced variant of the information display board techniques employed in the 1970s and 1980s by researchers within the descriptive JDM tradition (for a review, see Ford, Schmitt, Schechtman, Hults, \& Doherty, 1989). Like the information display boards, process-tracing software is mainly used to investigate information acquisition behavior with respect to depth, sequence, amount, and content of the search strategy (see Biggs, Rosman, \& Sergenian, 1993). However, the rapid development of information technology has made it possible to design more complex JDM situations, resulting in additional measures of decision behavior.

Computerized process tracing provides JDM researchers with several benefits. Software measures decision behavior accurately and reliably (Biggs et al., 1993; Lohse

The majority of this paper was prepared while I was a visiting research student at the Department of Social Psychology, London School of Economics and Political Science, during the spring semester of 2000. I am grateful for the Tom Hedelius scholarship from Handelsbanken Research Foundation, which made this stay possible. This research was made possible by grants from the Ruben Rausing Foundation for Research on New Firm Creation and Innovation and from the Sparbankerna Research Foundation. The author thanks Magnus Dahlberg, who did the computer programming and gave valuable comments about the design, and Jan Edman, who contributed important viewpoints with regard to the design and the programming. I also thank Lennart Sjöberg, Ingolf Ståhl, and Henry Montgomery for their helpful comments on earlier drafts of the paper. Lastly, I am obliged to Johan Wiklund, who provided me with data about his subset of samples. Comments by Robyn M. Dawes and Alice Isen are acknowledged. The author has a commercial interest in the software, but for a negotiable amount, academic researchers can purchase the P1 198 software from the author. Please note that all menus are written in Swedish. Correspondence concerning this article should be addressed to P. Andersson, Center for Economic Psychology, Stockholm School of Economics, P. O. Box 6501, SE 11383 Stockholm, Sweden (e-mail: ppa@hhs.se).
\& Johnson, 1996) by registering in log files the following decision behavior: acquired cues, time spent on examining those cues, response inputs, and total time spent on making the decision. It is possible to incorporate more factors, which creates richer and more complex information environments, as well as more interactions (Brucks, 1988). For instance, so-called computerized microworlds (e.g., NewFire and MORO) have been designed to study how people make series of interdependent decisions in a changeable world in which the changes occur autonomously and as a result of decisions made earlier (Brehmer, 1999). By setting up a local network or by using the Web, multiple participants can be investigated simultaneously, implying less tedious and less expensive data collection (Brucks, 1988). The participants may be randomly provided with access and passwords to the Web site.

Biggs et al. (1993) discussed two forms of invalidity of computerized process tracing. First, different computer practices among participants may threaten internal validity. Second, the inability of participants to view information simultaneously on several screens may make the task dissimilar to actual practice, thus limiting the researcher's ability to generalize findings and indicate task complexity. These objections must, however, be viewed in the light of people's increasing use of computers. In addition, the rapid increase of the World-Wide Web as a way to buy and sell products and services has meant not only that the process-tracing software has external validity, but also that empirical findings obtained by such software can be generalized (Lohse \& Johnson, 1996). It can, therefore, be argued that the possibilitiesfor JDM theories to reflect how people make decisions may have increased.

Searches in various literature databases indicated that there are three main process-tracing software programs: Search Monitor (Brucks, 1988), MouseLab (Johnson, Payne, Schkade, \& Bettman, 1996), and two versions of Saad's $(1996,1998)$ device for collecting data in sequential choice environments. These programs are designed to deal with varying but artificial JDM tasks. In addition, sev- 
eral computer interfaces have been constructed for specific experimental designs. For instance, Hoch and Schkade (1996) employed a computerized forecasting task to examine the accuracy of pattern-matching strategies. Despite the potential for getting insights into JDM, there seem to be few process-tracing softwares especially designed for certain real-world JDM tasks. An exception is INFOCUS, which is a windows-based computer program developed to assist auditors (Davis, 1996).

In the present paper, I will describe a software program especially designed to capture professionals' decision behavior in a real business context. Using this software, participants decide whether a loan proposition concerning a small firm should be granted or denied. This is an important and realistic business JDM task. I also will give an example of an analysis of preliminary data collected by the present software.

The remainder of the paper is organized in four sections. First, the rationale for developing the software is described. Second, the software is described. Third, an example of possible analyses of the data captured by the software is reported. Fourth, the paper ends with a discussion.

\section{RATIONALE FOR DEVELOPING THE P1198 SOFTWARE}

The process-tracing P1 198 software has been especially designed to investigate how experienced loan officers make decisions about loan propositions concerning small firms. The name P1198 refers to the fact that the development of this software started in November 1998. Besides being designed as a process-tracing device, the software may be well suited to be employed as a pedagogical tool in educating novice and experienced credit analysts, because it gives insights into decision behavior. With such insights, it might be possible to improve JDM as regards granting credit to small firms.

The design was motivated by two circumstances. First, small firms are hard to assess, mainly because of the following factors: (1) the traditional analyses of financial ratios reflect the future performance of small firms poorly (Keasey \& Watson, 1987); (2) loan officers thus have to rely on other kinds of information that are ambiguous (Altman, 1983); (3) empirical research on bankruptcy cannot be generalized to small firms, owing to their special characteristics, such as high variance in expected returns (Hall, 1992). Second, insights into how experienced loan officers make lending decisions are crucial to developing training programs for novice loan officers and to constructing expert systems (see Shanteau \& Stewart, 1992). Such insights may also improve economic efficiency (see Camerer, 1995) in, that the number of incorrect decisions might be decreased, implying a more efficient capital allocation to small firms (see Cressy \& Olofsson, 1997).

Like the other process-tracing software, P1198 takes into consideration that decision making is a sequential process spanning four stages (see Einhorn \& Hogarth,
1980): acquiring information, evaluating the acquired information, deciding to acquire additional information, and making the final decision. The sequence of the stages does not necessarily reflect the way decision makers actually make decisions. March (1994) has argued that the decision maker acquires information, makes the decision, and then acquires more information in order to justify the decision made. Thus, the P1198 software is flexible, so the participant can acquire information and make a decision in whatever sequence.

In contrast to the aforementioned programs, the P1198 software has strong external validity because it has been designed to reflect a specific decision domain. Viewpoints from experienced loan officers and empirical research findings on lending (Altman, 1983; Andersson, 2001; Argenti, 1976; Beaulieu, 1996; Hedelin \& Sjöberg, 1995) ensured a strong fit between the experimental world and the real word (see Beach, 1992).

\section{DESCRIPTION OF THE SOFTWARE P1198}

The P1198 software is run on a Web browser (e.g., Internet Explorer 5) that must be connected to a special server (i.e., Lotus Domino). ${ }^{1}$ The source code was written in Lotus Notes. The software consists of two interacting systems: a database of the three loan propositions and a user interface. Collected data on decision behavior are stored in $\log$ files.

\section{The Loan Proposition Database}

The database includes three loan propositions, with information about three real but anonymous small firms. The three small firms have been selected from a small sample $(n<25)$ that was randomly drawn from the stratified sample of 465 small firms used by Wiklund (1998), who collected his data in 1996. One of these three companies constitutes a warm-up case used for practical purposes. The other two companies represent the propositions used to capture decision behavior. The first proposition concerns a solvent small firm producing lifting devices, with a turnover of about $\$ 3.5$ million for the last year (1996) and an applied amount of $\$ 294,000$. The second proposition concerns an insolvent small firm producing metallurgy products, with a turnover about $\$ 1.6$ million for the last year and an applied amount of $\$ 235,000$.

In contrast to earlier studies performed within the descriptive JDM tradition involving, at the most, 12 cues (Ford et al., 1989), a participant can consider a total of 74 cues in the P1198 software before making a decision. Table 1 describes the available information in the database. The accounting information, consisting of balance sheets, income/cost reports, and financial ratios, was taken from credit reports proved by a Swedish credit-rating agency. The financial cues spanned 3 adjacent years. Since the credit reports had abundant information, some simplifications were made to decrease the number of financial cues. For each loan proposition, the database provides the participant with a total of 57 financial cues. It must be 
Table 1

The Available Information in the P1198 Software

\begin{tabular}{|c|c|c|c|}
\hline Category of Information & & Content of Cues & \\
\hline $\begin{array}{l}\text { Accounting information: } \\
\text { balance sheet } \\
\text { ( } 21 \text { cues) }\end{array}$ & $\begin{array}{l}\text { Fixed assets } \\
\text { Land, buildings, and } \\
\quad \text { improvements } \\
\text { Plant and equipment } \\
\text { Total fixed assets } \\
\text { Inventories } \\
\text { Trade accounts receivable } \\
\text { Other accounts receivable }\end{array}$ & $\begin{array}{l}\text { Liquid assets } \\
\text { Total current assets } \\
\text { Total assets } \\
\text { Share capital } \\
\text { Legal reserves } \\
\text { Retained earnings } \\
\text { Net income for the year }\end{array}$ & $\begin{array}{l}\text { Total shareholders' equity } \\
\text { Total untaxed reserves } \\
\text { Long-term debt } \\
\text { Accounts payable-trade } \\
\text { Other current liabilities } \\
\text { Total liabilities } \\
\text { Total shareholders' equity and } \\
\quad \text { liabilities }\end{array}$ \\
\hline $\begin{array}{l}\text { Accounting information: } \\
\text { income/cost report } \\
\text { ( } 11 \text { cues })\end{array}$ & $\begin{array}{l}\text { Sales } \\
\text { Cost of goods sold } \\
\text { Depreciation } \\
\text { Earnings before interest and } \\
\quad \text { taxes }\end{array}$ & $\begin{array}{l}\text { Financial income } \\
\text { Financial expenses } \\
\text { Income from ordinary activities } \\
\text { Nonrecurring income and } \\
\quad \text { expenses }\end{array}$ & $\begin{array}{l}\text { Special adjustments } \\
\text { Taxes } \\
\text { Net income for the year }\end{array}$ \\
\hline $\begin{array}{l}\text { Accounting information: } \\
\text { financial ratios } \\
\text { ( } 25 \text { cues })\end{array}$ & $\begin{array}{l}\text { Return on equity } \\
\text { Return on total assets } \\
\text { Average interest rate on debt } \\
\text { Gross margin } \\
\text { Profit margin } \\
\text { Net margin } \\
\text { Interest coverage ratio } \\
\text { Working capital turnover } \\
\text { Cash-flow-to-total-cost ratio }\end{array}$ & $\begin{array}{l}\text { Cash-flow-to-total-debt ratio } \\
\text { Rate of self-financing } \\
\text { Inventory turnover rate } \\
\text { Annual sales per employee } \\
\text { Ratio of personnel costs to annual } \\
\text { sales } \\
\text { Ratio of working capital to } \\
\text { annual sales } \\
\text { Ratio of accounts receivable to } \\
\text { annual sales }\end{array}$ & $\begin{array}{l}\text { Ratio of average inventory to } \\
\text { annual sales } \\
\text { Ratio of current liabilities to } \\
\quad \text { annual sales } \\
\text { Average collection period } \\
\text { Average supplier credit period } \\
\text { Current ratio } \\
\text { Acid test ratio } \\
\text { Equity-asset ratio } \\
\text { Capitalization rate } \\
\text { Debt-equity ratio }\end{array}$ \\
\hline $\begin{array}{l}\text { Nonaccounting or qualitative } \\
\text { information } \\
\text { (17 cues) }\end{array}$ & $\begin{array}{l}\text { Business } \\
\text { The purpose of the proposition } \\
\text { Managing director } \\
\text { Board of directors } \\
\text { Customers }\end{array}$ & $\begin{array}{l}\text { Competitors } \\
\text { Products } \\
\text { Development of industry } \\
\text { Suppliers } \\
\text { 1-year prognosis } \\
\text { 5-year prognosis }\end{array}$ & $\begin{array}{l}\text { Accountant } \\
\text { Collateral } \\
\text { Auditor's report } \\
\text { Employees } \\
\text { Salaries } \\
\text { Credit rating }\end{array}$ \\
\hline
\end{tabular}

Note-The cues in each category of information appear from left to right in the sequence in which they appear on the screen. In addition, the financial cues are reported in the traditional sequence. All accounting cues are numbers. Most of the nonfinancial cues are written as very short statements.

emphasized that all these cues represent the information that is accessible to loan officers in the real world.

The 17 nonaccounting cues were derived from two main sources. First, some responses to the questionnaires employed by Wiklund (1998) were used. The questionnaires included several questions about the company, the board of directors, the decision style of management, the industry, and the business environment. Responses to those questions are essential for accurate credit assessments. Second, the credit-rating agency provided some data. To facilitate reading and understanding, these statements were written in a simple and straightforward manner with short sentences and simple words. For instance, the range of the number of words for the nonfinancial information spans between a minimum of 2 words (i.e., "certificate auditor") and a maximum of 41 words (i.e., the description of the manager). It must be emphasized that the selection of the nonfinancial information has been done in accordance with research findings, as well as discussions with loan officers.

\section{User Interface}

The user interface is window driven and consists of the following interacting components: (1) an introductory screen, (2) a short questionnaire screen, (3) a loan proposition menu, (4) four menus for the information cate- gories, (5) a decision menu, and (6) a pop-up window. In principle, the components interact in the sequence as follows. Figure 1 shows a flowchart summary of the P1198 software's interactive flow.

Introductory screen. The P1198 software starts with an introductory screen informing the participant about the purpose of the research project (i.e., to investigate loan officers' credit assessment of small firms). This screen also informs the participant that he or she is asked to make decisions about two loan propositions on the basis of four categories of information that have been reported by an assumed colleague: balance sheet, income/cost report, financial ratios, and qualitative information. Besides a short instruction on how to operate the software, the participant is also told that clicking on special buttons activates the hidden cues to the individual information categories. (An overview of the cues on paper is placed alongside the computer.) Finally, the participant is instructed that a warm-up case will be used for practical purposes but that, before this case is presented, some short biographicalquestions will be asked. It is mentioned that the responses will be treated confidentially. The participant proceeds by clicking on a button.

Short questionnaire screen. The participant is asked to state his or her name, age, gender, education, and years of experience with credit assessment and to specify what 


\section{Introductory screen}

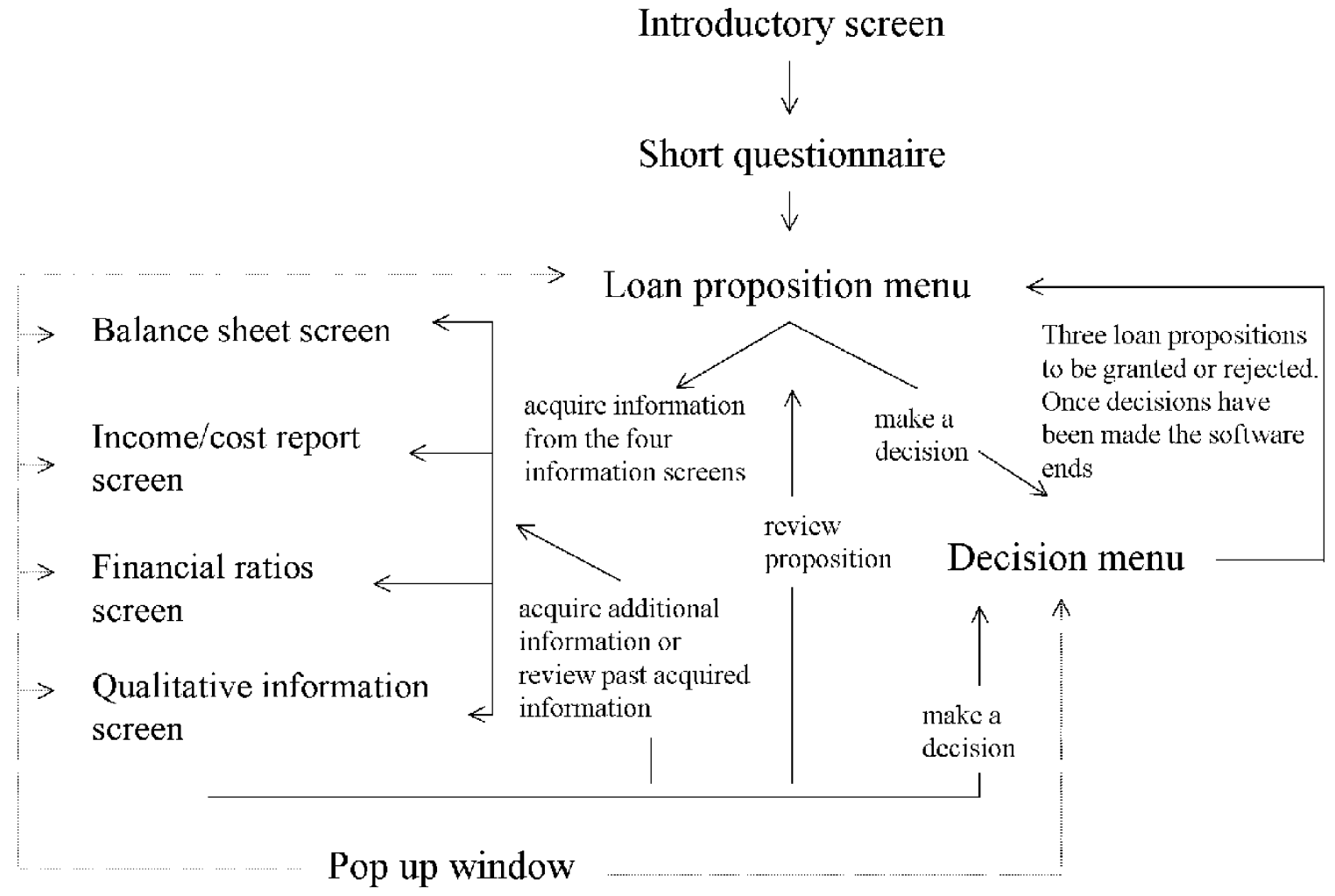

appears automatically at intervals and asks subjects to state concurrent judgment

Figure 1. Flowchart of the processing tracing the P1998 software's interaction flow. The dotted lines represent interactions that occur automatically, whereas the unbroken lines denote participant interactions.

industries he or she has assessed before. When he or she has responded to all the questions, he or she proceeds by clicking on a button.

Loan proposition menu. This menu describes briefly (37-59 words) the company and the demanded amount of the loan. In addition, this menu informs the participant that "by means of available information, your task is to make a decision about this loan proposition." In the top of this menu, there is a toolbar for the following menus: (1) the loan proposition menu, (2) four screens for each category of information, and (3) a decision screen. The participant can jump back and forth between these five menus in any sequence.

Information screens. The four menus on the aforementioned toolbar represent the four information categories (see Table 1). All the cues are hidden, so that information acquisition behavior can be captured. By clicking a mouse, the participant activates the cues one by one. For instance, to view the financial cue "Return on equity," the participant clicks on a button, and then the figures for 3 subsequent years are shown. The other cues are activated in a similar way, except that the nonaccounting cues do not display figures but written statements. Once a cue has been activated, it remains so. For an example of one of the information screens, see Figure 2.
Pop-up window. At intervals of a predetermined time period (e.g., 2 min) the pop-up window appears automatically. To the present author's knowledge, the pop-up window is unique for the P1198 software. However, this technique connects to the sliding bar employed by Saad $(1996,1998)$ to measure cumulative confidence in the artificial choice between two apartments, as well as to the experimental designs employed within research on predecisional distortion (see Russo, Meloy, \& Husted Medvec, 1998). The aim of the pop-up window is to investigate the ongoing decision process by asking the participant, at intervals, to state his or her current judgment on a 7-point verbally anchored scale ranging from loan is absolutely denied (0) to loan is absolutely granted (6). The scale has a neutral point (3), implying that the participant is doubtful.

Some criticisms can be raised about this approach of asking participants at intervals about their concurrent judgment, because this approach might unintentionally influence the decision process. First, a participant might search for confirmatory, rather than disconfirmatory, information and thus be a victim of the well-known confirmation bias (Plous, 1993). Second, a participant can actually distort diagnostic information and thus be a victim of predecisional distortion bias (Russo et al., 1998). Third, cognitive dissonance might be created, resulting in ef- 


\begin{tabular}{llllll}
\hline Balance & Income/Cost & Financial & Qualitative & Loan & Decision \\
Sheet & report & Ratios & Information & proposition & Menu \\
\hline
\end{tabular}

SHE: BUSINESS

THE PURPOSE OF THE The purpose is to improve the long-term and short-term credit by PROPOSITION increasing bank loan and decreasing the more expensive suppliers' eredit and the short-term debts.

MANAGING DIRECTOR I'he company has had the same managing director for three years. He is one of the founders. 'The managing director is 40 years old and has a great deal of experience in the trade. IIe has upper secondary school education and has earlier been the managing direetor for a company with 40 cmployecs. He is also an adviser, member of the board and owner of another company.

SEE BOARD OF DIRECTORS

CUSTOMERS Only sales to business. More than $95 \%$ is export sales. The three biggest customers account for $25-50 \%$ of the sales. Loyal three-year customers account for $75-95 \%$ of the sales. According to the managing director, the demand is somewhat easy to predict.

\section{SHE, COMPH,ITTORS}

\section{SEE PRODUCTS}

Figure 2. The qualitative information screen (translated from Swedish). The cues appear in the order described in Table 1. Cues with a so-called SEE-button have not been activated and, accordingly, remain hidden. A toolbar exists in the top of the screen, and a scroll bar appears on the right side of the screen. To view the other qualitative cues, the participant scrolls down. The revealed cues represent the warm-up case.

forts to reduce that dissonance by neglecting or boosting information (Festinger, 1957). Fourth, the approach differs also from real-world practice, since people are seldom asked to state concurrently their decision processes. Nevertheless, it is argued that the pop-up window has limited influence and provides valuable insights into how credit decisions are made.

Decision screen. When the participant has made up his or her mind, he or she moves to the decision screen, where he or she is asked to grant or deny the loan proposition. If a loan is granted, he or she is asked to state the interest rate and the number of years of amortization, as well as to write an explanation as to why the loan was granted. On the other hand, if a loan is denied, the participant is asked for his or her motivation for rejecting the loan proposition and what complementary information, if any, would be required. For both kinds of decisions, the participant is asked to rate his or her confidence in the decision on a 7-point verbally anchored scale ranging from absolutely unsure (0) to absolutely sure (6).
Once the participant has made a decision and written an explanation, he or she proceeds by clicking on a button. Then he or she is asked to proceed with the next loan proposition, and the loan proposition screen appears. This procedure is repeated until the participant has made decisions about all three loan propositions.

\section{Collected Data on Decision Behavior}

A $\log$ file registers, in chronological order, the participant's decision behavior regarding each loan proposition. It can be argued that the log file is a blueprint of the decision process (see Biggs et al., 1993). In particular, the log file contains the following decision behavior: the participant's inputs, such as responses to the biographical questions and to the pop-up window, his or her decision, the confidence rating, and the interest rate and years of amortization if the proposition was granted, as well as written explanations; the acquired cues and the sequence in which the cues were acquired; the sequence in which the participant navigated the different screens; the sec- 
onds spent on acquiring cues and examining the different screens.

A short analysis of the log file can be viewed in a Lotus Notes document, and it is possible to export the $\log$ file to Microsoft Excel. The log file can be better arranged in Excel and then transferred to a statistical software program (e.g., SPSS), where more powerful analyses can be performed. Because the P1198 software provides a vast amount of data on decision behavior stored in $\log$ files, it is important to know in advance what kind of analyses to perform. It is otherwise easy to get lost in the data.

\section{AN EXAMPLE OF AN ANALYSIS OF LOG FILES}

This section reports the results of tentative analyses of $\log$ files for 2 experienced loan officers' decision behavior, to illustrate the insight into JDM provided by the P1198 software.

Table 2 summarizes the captured decision behavior. The 2 participants made identical decisions: They rejected the two propositions. As regards the confidence and time spent on making decisions, there was some variability. For example, with respect to the first proposition, Loan Officer 1 acquired a total of 47 cues $(63.5 \%$ of all the available cues) and 8 for financial ratios. On the other hand, Loan Officer 2 acquired almost the same amount of information, 46 cues $(62.2 \%)$, as well as almost the same amount of cues for financial ratios. As the depth of information acquisition indicates, Loan Officer 1 tended to acquire more cues for the balance sheet, as well as for the income and cost report, but fewer qualitative cues than Loan Officer 2 did. It follows that Loan Officer 1 (2) was prone to rely on financial cues (qualitative cues).

Figure 3 reports results from the pop-up window. Besides the time measure, the graphs show two important points: (1) the first impression of the loan proposition and (2) how that impression was influenced by acquisition of information. The first impression might reflect the initial attitude toward making lending decisions. As Figure 3 indicates, Loan Officer 1 was doubtful, whereas Loan Officer 2 had a somewhat positive attitude toward granting loans. Acquisition of cues influenced the first impression. Loan Officer 1 was uncertain about the first loan proposition for almost $12 \mathrm{~min}$, although he had acquired $50 \%$ of the available cues. He then acquired an additional $12 \%$ of the cues (i.e., financial ratios and the cue about collateral) and arrived at a decision to reject. Loan Officer 2, on the other hand, was positive for about $8 \mathrm{~min}$, but after acquiring cues for the balance sheet and financial ratios, he rejected the proposition. The loan officers acquired the cues in a similar sequence $(r s=.64)$. In addition, the motivations for their decisions were similar, in the sense that they both stressed low profitability and low equity/asset ratio.

As regards the second proposition, Loan Officer 1 had a variable attitude. Initially, he was doubtful. Next, he tended to reject the proposition while acquiring cues for the income/cost report. After acquisition of cues for the balance sheet, he was doubtful again. Then, just as for the first proposition, he acquired financial ratios and decided to reject. In contrast, Loan Officer 2 followed more or less the same pattern as he did for the first proposition - that is, he was positive while viewing the qualitative cues, but he rejected after considering some financial ratios. The loan officers acquired cues in almost the same sequence $(r \mathrm{~s}=.67)$. In connection with this, it should be mentioned that they had high degrees of internal consistency in terms of the sequence in which the cues were acquired $(r s>.98)$.

To sum up, the results of the tentative analysis are consistent with the assumptions that there should be consensus among expert judges (see Einhorn, 1974) and that experts do not rely on a large amount of information (see Shanteau, 1992). In addition, the results illustrate two approaches to making credit assessments of small businesses: a focus on financial cues and one on qualitative information. Note that, regardless of approach, the participating loan officers arrived at the same decisions. It can also be argued that the results support the idea that

Table 2

Decision Behavior Concerning Two Experienced Loan Officers Captured by the P1198 Software

\begin{tabular}{|c|c|c|c|c|c|}
\hline \multirow[b]{2}{*}{ Decision Behavior } & \multirow{2}{*}{$\begin{array}{c}\text { Total } \\
\text { Available Cues }\end{array}$} & \multicolumn{2}{|c|}{ Loan Proposition 1} & \multicolumn{2}{|c|}{ Loan Proposition 2} \\
\hline & & Loan Officer 1 & Loan Officer 2 & Loan Officer 1 & Loan Officer 2 \\
\hline Decision & & Deny & Deny & Deny & Deny \\
\hline Confidence & & Very sure & Absolutely unsure & Absolutely sure & Somewhat sure \\
\hline Total time spent on decision making (in seconds) & & 994 & 453 & $866^{\circ}$ & 598 \\
\hline \multicolumn{6}{|l|}{ Amount of acquired information } \\
\hline Total acquired cues for balance sheet & 21 & 17 & 13 & 18 & 15 \\
\hline Total acquired qualitative cues & 17 & 12 & 17 & 10 & 17 \\
\hline Total acquired cues in income/cost report & 11 & 10 & 7 & 7 & 5 \\
\hline Total acquired cues in financial ratios & 25 & 8 & 9 & 9 & 4 \\
\hline Total acquired cues & 74 & 47 & 46 & 44 & 41 \\
\hline \multicolumn{6}{|l|}{ Depth of acquisition } \\
\hline Acquired cues for balance sheet & 21 & $81.0 \%$ & $61.9 \%$ & $85.7 \%$ & $71.4 \%$ \\
\hline Acquired cues for income/cost report & 11 & $47.6 \%$ & $33.3 \%$ & $33.3 \%$ & $23.8 \%$ \\
\hline Acquired cues for financial ratios & 25 & $38.1 \%$ & $42.9 \%$ & $42.9 \%$ & $19.0 \%$ \\
\hline Acquired financial cues & & $55.7 \%$ & $48.0 \%$ & $56.8 \%$ & $39.3 \%$ \\
\hline Acquired cues for qualitative information & 17 & $57.1 \%$ & $81.0 \%$ & $47.6 \%$ & $81.0 \%$ \\
\hline
\end{tabular}


Loan proposition 1: Loan officer I

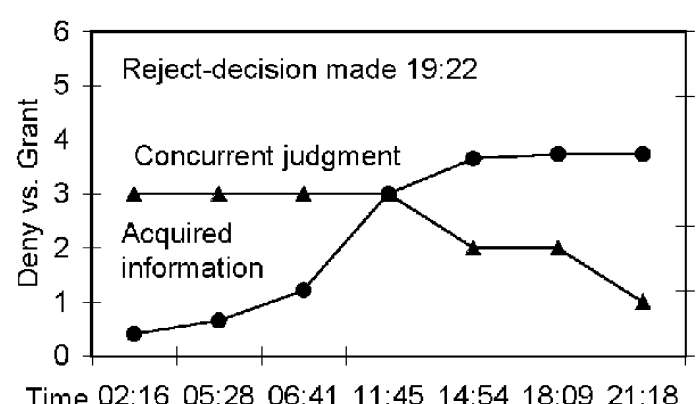

Loan proposition 2: Loan officer 1
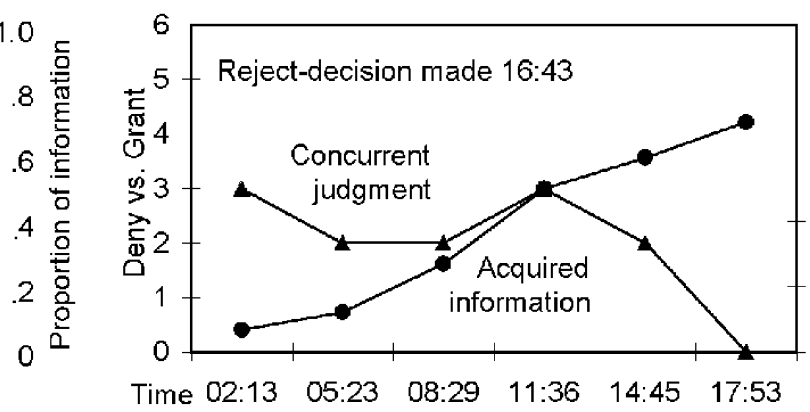

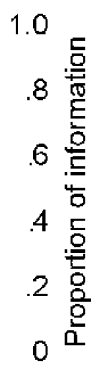

Loan proposition 2: Loan officer 2
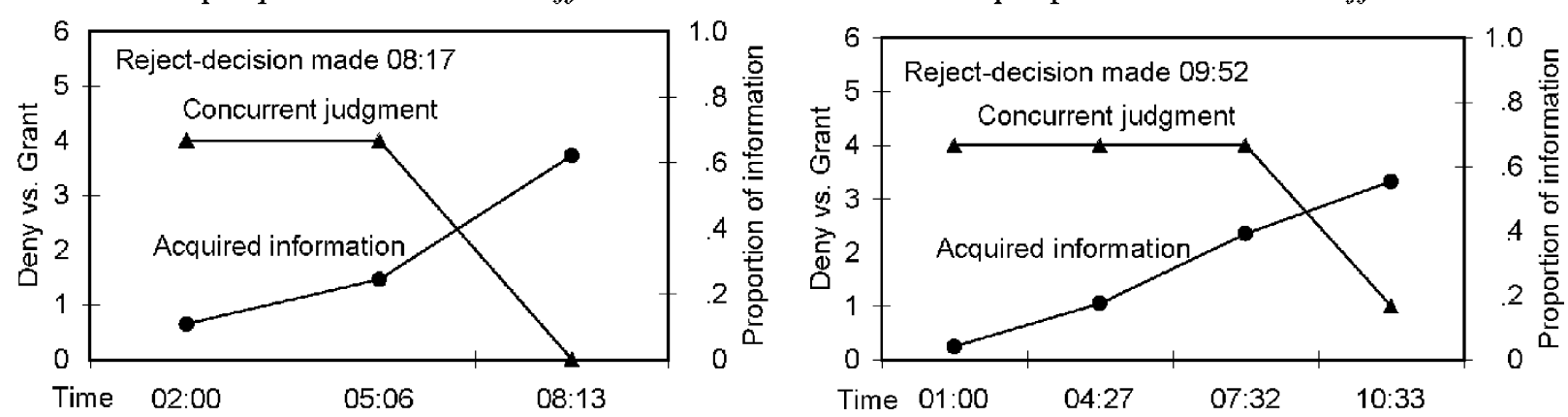

Figure 3. Decision processes and amount of acquired information from 2 experienced loan officers. The graphs show the first impression of the propositions and how that impression was influenced by information acquisition. The horizontal axis indicates minutes. The left vertical axis measures concurrent judgment on a 7 -point scale ranging from deny absolutely (0) to grant absolutely (6). The midpoint (3) of this axis corresponds to dubious. The right vertical axis measures the accumulated amount of acquired information (defined as the number of acquired cues divided by the total number of available cues). Owing to minor technical problems, some intervals deviated from $3 \mathrm{~min}$. The observant reader may note that the time for the final decision deviates from the time spent on decision making as reported in Table 2 . The reason is that the stated time in Table 2 also included the time the participants spent giving motivations for their decisions.

the decision process should be viewed as a search for a dominance structure (see Montgomery, 1989) and as consisting of stages of differentiation and consolidation (see Svenson, 1996). However, it must be emphasized that caution must be observed in drawing conclusions from these results, because the data were restricted to only 2 loan officers and a preliminary version of the P1198 software was employed.

\section{DISCUSSION}

In this paper, I have described the P1198 software designed to capture professionals' decision behavior as regards lending to small businesses. Although this software might be argued to concern a narrowly defined decision domain, it should be of interest to researchers employing computerized process tracing. For example, the inclusion of a large number of cues and the use of a pop-up window as a tool to capture the ongoing decision process may stimulate future designs of process-tracing software. The tentative analysis of $\log$ files may also be of some interest.
At present, the P1198 software has been used to study the effect of experience on decision behavior in lending (Andersson, 2001). In this study, three groups of participants (19 business students, 19 intermediately experienced loan officers, and 23 highly experienced loan officers) interacted with the software. Among other things, the study indicated that highly experienced loan officers tended to acquire an extensive number of cues and took more time than did students. In an attempt to evaluate the validity of the software, a follow-up questionnaire was handed out to the 42 loan officers. Their responses indicated that they believed that the loan propositions included sufficient information and were realistic, an indication that observations made by the P1198 software have some external validity.

There are some limitations associated with the P1198 software. Despite the large number of cues available, some loan officers remarked that they missed the encounter with the client (Andersson, 2001). One can also argue that the software shapes participants to be passive information collectors, because it defines what information 
to acquire and does not allow the participant to request additionalinformation (see Raynard \& Williamson, 2000). In real life, loan officers encounter the clients, demand more information, consider the revenues from granting loans, and rely on portfolio thinking.

Some improvements of the P1198 software may be required. At present, the loan database includes only three loan propositions, so efforts might be devoted to expanding that database to include more propositions, although such efforts are tedious and time consuming. Information about the revenue associated with each loan proposition (given that the loan is granted) might be added. Another improvement would be to change the decision task from one involving granting or rejecting a loan proposition to, in contrast, one involving risk assessment (McNamara \& Bromiley, 1999). This would be achieved by replacing the present categorical scale with a 7-point scale ranging from low risk (1) to high risk (7) in the decision menu. Finally, efforts should be devoted to computerizing the analyses of $\log$ files, so that a participant can instantaneously obtain a graphical illustration of his or her decision behavior regarding each loan proposition.

Future research may deal with further validation studies. For instance, such a study might aim at examining to what extent observations of decision behavior made by the P1198 software differ from those made by think-aloud protocols. This study would involve two experimental settings: One group of participants performs the task in the software without verbalizing their thoughts, whereas another group thinks aloud while making judgments and decisions about the same loan propositions, which are presented in paper form. With reference to Biggs et al. (1993), it is likely that this procedure would show that computerized process tracing and verbal protocol give insights into the acquisition of and the use of information, respectively. The procedure could also evaluate to what extent the pop-up window influences the decision process.

The P1 198 software has, nevertheless, external validity. Loan officers are, in real life, confronted with the majority of the cues in the present format. In addition, some banks might implement procedures in which subordinates send documents concerning loan propositions via the Web to their senior loan officer so that he or she can make the final decision. Devices such as P1198 could then be easily set up. The decision behavior stored in log files would then attract not only JDM researchers, but also internal auditors who might ask why a loan was granted.

\section{REFERENCES}

Altman, E. I. (1983). Corporate financial distress: A complete guide to predicting, avoiding, and dealing with bankruptcy. New York: Wiley. ANDERsson, P. (1998). Experto credite: Three papers on experienced decision-makers. Licentiate thesis, Stockholm School of Economics. Andersson, P. (2001). Does experience matter in lending? A processtracing study on experienced loan officers' and novices' decision behavior. Manuscript in preparation.

Argenti, J. (1976). Corporate collapse: The causes and symptoms. London: McGraw-Hill.
BEACH, L. R. (1992). Epistemic strategies: Casual thinking in expert and nonexpert judgment. In F. Bolger \& G. Wright (Eds.), Expertise and decision support (pp. 107-127). New York: Plenum.

BeAulieu, P. R. (1996). A note on the role of memory in commercial loan officers' use of accounting and character information. Accounting, Organizations, \& Society, 21, 515-528.

Biggs, S. F., Rosman, A. J., \& Sergenian, G. K. (1993). Methodological issues in judgment and decision-making research: Concurrent verbal protocol validity and simultaneous traces of process. Journal of Behavioral Decision Making, 6, 187-206.

BREHMER, B. (1999). Reasonable decision making in complex environments. In P. Juslin \& H. Montgomery (Eds.), Judgment and decision making: Neo-Brunwikian and process-tracing approaches (pp. 922). Mahwah, NJ: Erlbaum.

BRUCKS, M. (1988). Search Monitor: An approach for computer-controlled experiments involving consumer information search. Journal of Consumer Research, 15, 117-121.

CAmerer, C. (1995). Individual decision making. In J. H. Kagel \& A. E. Roth (Eds.), Handbook of experimental economics (pp. 587-703). Princeton, NJ: Princeton University Press.

Cressy, R., \& Olofsson, C. (1997). European SME Finance: An overview. Small Business Economics, 9, 87-96.

DAVIS, J. T. (1996). Experience and auditors' selection of relevant information for preliminary control risk assessment. Auditing: A Journal of Practice \& Theory, 15, 16-37.

EinHorn, H. J. (1974). Expert judgment: Some necessary conditions and an example. Journal of Applied Psychology, 59, 562-571.

Einhorn, H. J., \& Hogarth, R. M. (1980). Behavioral decision theory: Processes of judgment and choice. Annual Review of Psychology, 32, 53-88.

Festinger, L. (1957). A theory of cognitive dissonance. Stanford, CA: Stanford University Press.

Ford, J. K., Schmitt, N., Schechtman, S. L., Hults, B. M., \& DoHERTY, M. (1989). Process tracing methods: Contributions, problems, and neglected research questions. Organizational Behavior \& $\mathrm{Hu}$ man Decision Processes, 43, 75-117.

HALl, G. (1992). Reasons for insolvency amongst small firms: A review and fresh evidence. Small Business Economics, 4, 237-250.

Hedelin, L., \& SJöBERG, L. (1995). Bankers' judgment of loan applicants in regard to new ventures. In B. Green (Ed.), Risky business (pp. 67-94). Stockholm: Stockholm University Press.

Hoch, S. J., \& SchKadE, D. A. (1996). A psychological approach to decision support systems. Management Science, 42, 51-64.

Johnson, E. J., Payne, J. W., Schinde, D. A., \& Bettman, J. R. (1996). A mouse-based software system for doing consumer behavior and decision making research. Available: http://www-marketing. wharton.upenn.edu/ mouselab/. [Retrieved: November 1997]

KeASEY, K., \& WATSON, R. (1987). Non-financial symptoms and the prediction of small company failure: A test of Argenti's hypothesis. Journal of Business, Finance \& Accounting, 14, 335-354.

Lohse, G. L., \& Johnson, E. J. (1996). A comparison of two process tracing methods for choice tasks. OrganizationalBehavior \& Human Decision Processes, 68, 28-43.

MARCH, J. G. (1994). A primer on decision making: How decisions happen. New York: Free Press.

MCNamara, G., \& Bromiley,P. (1999). Risk and return in organizational decision making. Academy of Management Journal, 42, 330-339.

Montgomery,H. (1989). From cognition to action: The search for dominance in decision-making. In H. Montgomery \& O. Svenson (Eds.), Process and structure in human-decision making (pp. 23-49). Chichester, U.K.: Wiley.

Plous, S. (1993). The psychology of judgment and decision making. New York: McGraw-Hill.

Raynard, R., \& Williamson, J. (2000, May). Conversation-based process-tracing methods for naturalistic decision making: Information search and verbal protocol analysis. Paper presented at the Fifth Conference on Naturalistic Decision Making, Stockholm.

Russo, J. E., Meloy, M. G., \& Husted Medvec, V. (1998). Predecisional distortion of product information. Journal of Marketing Research, 35, 438-452. 
SAAD, G. (1996). SMAC: An interface for investigating sequential multiattribute choices. Behavior Research Methods, Instruments, \& Computers, 28, 259-264.

SAAD, G. (1998). The experimenter module of the DSMAC (Dynamic Sequential MultiAttribute Choice) interface. Behavior Research Methods, Instruments, \& Computers, 30, 250-254.

ShanteaU, J. (1992). How much information does an expert use? Is it relevant? Acta Psychologica, 81, 75-86.

ShanteAU, J., \& STEWART, T. R (1992). Why study expert decision making? Some historical perspectives and comments. OrganizationalBehavior \& Human Decision Processes, 53, 95-106.

Svenson, O. (1996). Decision-making and the search for fundamental psychological regularities: What can be learned from a process per- spective. OrganizationalBehavior \& Human Decision Processes, 65 , 252-267.

WiKLUND, J. (1998). Small firm growth and performance: Entrepreneurship and beyond. Unpublished doctoral dissertation, Jönköping International Business School, Jönköping, Sweden.

\section{NOTE}

1. At the present time, the software has primarily been run and tested in Internet Explorer 5, but it might work with other Web browsers.

(Manuscript received October 13, 2000;

revision accepted for publication March 10, 2001.) 